Fonseca E Leite, 2019

Volume 5 Issue 2, pp. 68-84

Date of Publication: 27th August 2019

DOI-https://dx.doi.org/10.20319/mijst.2019.52.6884

This paper can be cited as: Fonseca, E. M. M., E Leite, P. A. S., (2019). Fire Design of Wood Connectıons Loaded in Shear. MATTER: International Journal of Science and Technology, 5(2), 68-84.

This work is licensed under the Creative Commons Attribution-Non Commercial 4.0 International License. To view a copy of this license, visit http://creativecommons.org/licenses/by-nc/4.0/ or send a letter to Creative Commons, PO Box 1866, Mountain View, CA 94042, USA.

\title{
FIRE DESIGN OF WOOD CONNECTIONS LOADED IN SHEAR
}

\author{
Elza M. M. Fonseca \\ LAETA, INEGI, Department of Mechanical Engineering, Polytechnic Institute of Porto, ISEP, \\ Porto, Portugal \\ elz@isep.ipp.pt \\ Pedro A. S. Leite \\ MSc in Mechanical Engineering, Polytechnic Institute of Porto, ISEP, Portugal \\ 1170021@isep.ipp.pt
}

\begin{abstract}
The main objective of this work is to compare the fire resistance between wood-steel-wood (W-S$W)$ and wood-wood-wood (W-W-W) connections, both joined by steel dowel fasteners, in double shear. The analytical and design procedures follow simplified equations presented in Eurocode 5, part 1-1 and 1-2. A computational methodology, based on finite element method, was also implemented to produce two dimensional thermal simulations, which permits to verify the heating effect through the dowels fasteners or steel elements through the connection in study. Different cross-sections will be identified, considered as the most relevant parts, to compare the temperature distribution in the studied connections. According to the fire exposure, a thermal and transient effect will happen and a char-layer appearing in the exposure side of the connections. The measured quantity of the charred area permits to identify the lost structural material in the studied cross-sections. The charring rate will calculate and compared with the constant value proposed by the Eurocode 5, part 1-2. There are typical values for the charring rate of wood between 0.51.0mm/min according to Eurocode 5, part 1-2. However, as a general conclusion and additional
\end{abstract}


information to help designers and professionals, the number of fasteners increases with the applied load, lower dowels diameters have higher effect in the number of fasteners, at fire exposure the steel fasteners bring the heat to inside the connections, and different wood densities affect the thermal behaviour and the charring rate evolution. The charring rate permits to quantify the lost layer thickness and the fire resistance of the connection, dependent on the chosen material density.

\section{Keywords}

Wood Connection, Wood, Steel Dowel, Char Layer, Fire

\section{Introduction}

Wood connections have been investigated due to their impact in construction engineering in terms of strength, ductility and all capability to increase the structural performance in service. In heavy timber structures, double-shear wood connections with steel fasteners are widely used to assembly structural members and transfer loads (Peng, Hadjisophocleous, Mehaffey \& Mohammad, 2011).

The wood connections exposed to fire develop a char layer that reduces the cross-section. At $100^{\circ} \mathrm{C}$, most of the water inside the wood evaporates, and when the temperature rises, the wood starts to lose some of their properties. When it finally reaches the $300^{\circ} \mathrm{C}$, a char layer is formed. The temperature limit of $300^{\circ} \mathrm{C}$ is the criterion of char layer formation, Eurocode 5 part 1-2, (CEN EN1995-1-2, 2004). The typical values for the charring rate of wood changes between 0.51.0mm/min. Eurocode 5 part 1-2, (CEN EN1995-1-2, 2004) suggests a charring rate equal to $0.65 \mathrm{~mm} / \mathrm{min}$ or $0.7 \mathrm{~mm} / \mathrm{min}$ for softwood or hardwood, with density higher than $290 \mathrm{~kg} / \mathrm{m}^{3}$. The evaluation of the char layer depends on the exposure time and determines the charring rate in $\mathrm{mm} / \mathrm{min}$. Several studies using the finite element method and experimental methodologies to analyse the evolution of charring rate and describe the fire performance in structural elements have been published for the authors of this work (Fonseca, Coelho \& Barreira, 2012), (Fonseca \& Gouveia, 2018). And recently some numerical approaches have been carried out to analyze the behaviour of wood connections, due to the possibility to assess different combined parameters (Martins \& Fonseca, 2018). In the literature, few numerical models have been published, and the majority of publications are based on mechanical approaches (Resch \& Kaliske, 2012). According this purpose, the principal objectives of the study were as follow: 
- To design wood connections in double-shear prepared to resist at fire conditions with safety and appropriate dimensions to transfer the imposed loads in the structural member.

- To present a 2D thermal approach to analyse the fire resistance in typical wood connections.

- To compare the fire resistance in connections with and without protection using different wood material densities.

To obtain different designed connections, this work is based on simplified and analytical equations to create a database and verified with numerical simulations in fire conditions. Different applied loads and dowel diameters were used, which demonstrated the results for a safe design of wood connections in double-shear at room and under fire conditions.

The final goal of this work is to increase the knowledge of the fire resistance in wood connections, and increase the results with numerical and thermal validations, where the authors of this work have different investigations, (Aissa, Fonseca \& Lamri, 2017), (Martins \& Fonseca, 2018), (Fonseca, Silva \& Leite, 2019).

\section{Fire Behaviour of Wood Connections in Accordance with Eurocode 5}

The design of wood connections under double-shear intends to determine the main dimensions (width, height and thickness of the wood plates and steel plate, minimum spacing and edge/end distances between the dowels and the wood plate). The number of dowels is an important parameter in the design of the connection with the arrangement in lines and columns.

During this study different parameters are considered: tensile applied load $E_{d}$, dowel diameters $d$, the wooden board thickness $t_{1}, t_{2}$ and steel plate thickness $t_{s}$. In order to calculate the dimension of the connection, the load was considered as parallel to the grain direction, (Martins \& Fonseca, 2018), (Fonseca, Silva \& Leite, 2019).

According to Eurocode 5, part 1-1 (CEN EN1995-1-1, 2004), the design tensile strength along the grain $f_{t, 0, d}$, must be equal or higher than the design tensile stress along the grain. The tensile strength represents a reduced value of the characteristic strength along the wood grain, due to the application of two safety factors: the modification factor for load duration and moisture content $k_{m o d}$, and the partial factor for material properties $\gamma_{M}$, according to equation 1 .

$$
f_{t, 0, d}=\frac{k_{\text {mod }} x f_{t, 0, k}}{\gamma_{M}}
$$


Considering $A_{s}$ the cross-section of the member, the design tensile stress along the grain $\sigma_{t, 0, d}$ is calculated using the equation 2, Eurocode 5, part 1-1 (CEN EN1995-1-1, 2004).

$$
\sigma_{t, 0, d}=\frac{E_{d}}{A_{s}}
$$

Also, using all proposed simplified equations from Eurocode 5, part 1-1 (CEN EN1995-11, 2004), and if the wood connection has a central steel plate (W-S-W), the characteristic loadcarrying capacity per shear plane and per fastener must be calculated using the equation 3 .

$$
F_{v, R k}=\min \left\{\begin{array}{c}
f_{h, 1, k} t_{1} d\left[\sqrt{2+\frac{4 M_{y, R k}}{f_{h, R k} d t_{1}^{2}}}-1\right]+\frac{F_{\alpha x, R k}}{4} \\
2,3 \sqrt{M_{y, R k} f_{h, 1, k} d}+\frac{F_{\alpha x, R k}}{4}
\end{array}\right.
$$

The characteristic load-carrying capacity per shear plane and fastener, for a wood-wood connection (W-W-W) with dowel fasteners is according to the simplified equations from Eurocode 5 part 1-1 (CEN EN1995-1-1, 2004), equation 4.

$$
F_{v, R k}=\min \left\{\begin{array}{c}
f_{h, 1, k} t_{1} d \\
0,5 f_{h, 2, k} t_{2} d \\
1,05 \frac{f_{h, 1, k} t_{1} d}{2+\beta}\left[\sqrt{2 \beta(1+\beta)+\frac{4 \beta(2+\beta) M_{y, R k}}{f_{h, R k} d t_{1}^{2}}-\beta}\right]+\frac{F_{\alpha x, R k}}{4} \\
1,15 \sqrt{\frac{2 \beta}{1+\beta}} \sqrt{2 M_{y, R k} f_{h, 1, k} d}+\frac{F_{\alpha x, R k}}{4}
\end{array}\right.
$$

where: $f_{h, 1, k}$ is the characteristic embedment strength in timber member; $M_{y, R k}$ is the characteristic yield moment of the fastener and $F_{\alpha x, R k}$ represents the characteristic axial withdrawal capacity of the fastener, Eurocode 5 part 1-1 (CEN EN1995-1-1, 2004).

The value of $M_{y, R k}$ is calculated according to the dowel diameter and the material strength of the bolt.

$$
M_{y, R k}=0,3 f_{u, k} d^{2,6}
$$

The value of the characteristic embedment strength in timber member, is obtained due to the value of the dowel diameter and the characteristic wood density $\rho_{k}$.

$$
f_{h, 1, k}=0,082(1-0,01 d) \rho_{k}
$$


Finally, with the calculation from $F_{v, R k}$, it is possible to obtain the number of the bolts, equation 7 .

$$
N=\frac{E_{d}}{F_{v, R d}}
$$

The arrangement between dowels are according to the calculated spacing: parallel to the grain of fastener and within one row $a_{1}$, perpendicular to the grain and between rows $a_{2}$, the distance between fasteners and loaded end $a_{3, t}$, and unloaded edge $a_{4}, c$, which varies according to the dowel diameter.

In this work different variables were considered and the designed connections at room temperature guarantee the applied tensile load.

The second step is to apply the Eurocode 5, part 1-2 (CEN EN1995-1-2, 2004), according to two different methodologies for safety verification under fire conditions: the simplified method or the reduced load method. In this paper the simplified method will be used in all wood connections.

The following calculations are presented for a fire occurrence, according to a time exposure of 30min, for unprotect connections. The first step shall be verifying if the connection has a fire resistance for the established time, if not, the geometry must be increased in wood cross-section, or using in addition an insulating material. The action design effect for an exposure fire $E_{d, f i}$ must be calculated. The conversion factor for slip modulus is nominated as $\eta_{f}$.

$$
E_{d, f i}=E_{d} \eta_{f}
$$

The design strength in fire $f_{d, f i}$, is calculated using the modification factor for fire $k_{\text {mod,fi }}$, and the partial factor for timber $\gamma_{M, f i}$. The value of $f_{20}$ corresponds to the wood strength multiplied by the coefficient $k_{f i}$.

$$
f_{d, f i}=k_{m o d, f i} \frac{f_{20}}{\gamma_{M, f i}}
$$

Using the equation 10 it is possible to verify if the connection resists $30 \mathrm{~min}$ under fire.

$$
\frac{E_{d, f i}}{A_{s}}<f_{d, f i}
$$

In case the above equation is not verified, one of two solutions must be chosen: add wood material to the cross-section or add insulating material. 
For unprotect connection, Eurocode 5, part 1-2 (CEN EN1995-1-2, 2004) ensures a time of the fire resistance, $t_{d, f i}$, according with the connector. For dowels, this time is $20 \mathrm{~min}$, however the minimum value for $t_{1}$ is $45 \mathrm{~mm}$.

The extra thickness of the member for improved a fire resistance in the connections $a_{f i}$, is obtained following the equation 11.

$$
a_{f i}=\beta_{n} k_{f l u x}\left(t_{r e q}-t_{d, f i}\right)
$$

The $\beta_{n}$ value is the design charring rate under fire exposure, $k_{f l u x}$ is the heat flux coefficient for fasteners, and at last, $t_{r e q}$ represents the required time of fire resistance.

A worksheet with all parameters was developed, which permits verify the load-carrying capacity of the connection, the cross-section, the number of fasteners, the minimum spacing in edges and the resistance to the fire, per each situation in study, conducted according the Eurocode 5, part 1-1 (CEN EN1995-1-1, 2004) and Eurocode 5, part 1-2 (CEN EN1995-1-2, 2004).

The results show that every designed unprotected connection resists after 30min of fire exposure. For more fire resistance, the connections were protected with $18 \mathrm{~mm}$ of gypsum plasterboard type $\mathrm{F}$ and $23 \mathrm{~mm}$ of gypsum type $\mathrm{A}$ or $\mathrm{H}$, on affected the exposed surface, correspondent to the minimum value for $h_{p}$ to delay the charring rate for a $60 \mathrm{~min}$ fire exposure according to the Eurocode 5, part 1-2 (CEN EN1995-1-2, 2004).

For connections with an insulating material, the Eurocode 5, part 1-2 (CEN EN1995-1-2, 2004) gives two options for the material: gypsum (type A, F or H) or wood-based panels. For each one, it is presented with different equations. The value $t_{c h}$ refers to the delay of the start of charring rate due to protection, $h_{p}$ is the fire protective panel thickness.

For gypsum, type A or H:

$$
\begin{array}{r}
t_{c h} \geq t_{r e q}-0,5 t_{d, f i} \\
h_{p}=\frac{t_{c h}+14}{2,8}
\end{array}
$$

For gypsum, type F:

$$
\begin{array}{r}
t_{c h} \geq t_{r e q}-1,2 t_{d, f i} \\
h_{p}=\frac{t_{c h}+14}{2,8}
\end{array}
$$




\subsection{Steel Thermal Properties}

Figures 1 and 2 present the thermal conductivity and specific heat of steel. Steel is according the Eurocode 3, part 1-2 (CEN EN1993-1-2, 2005).

The density of steel remains constant with temperature, equal to $7850 \mathrm{~kg} / \mathrm{m}^{3}$. The emissivity of the material was considered equal to 0.7 .

\subsection{Wood Thermal Properties}

Figures 3, 4 and 5 present the thermal conductivity, specific heat and density of wood according to Eurocode 5, part 1-2 (CEN EN1995-1-2, 2004).

Three different wood species in homogeneous glued laminated (glulam) were considered for the designed connections, where the density properties vary between 370 and $480 \mathrm{~kg} / \mathrm{m}^{3}$. (CEN BS EN1194, 1999) lists eight glulam strength classes. To distinguish them from the timber categories, they are designated by GLxh as homogeneous lay-up, meaning that all of the laminations are of the same grade (strength class) and species (or species combinations), or GLxc as combined, where the cross-section comprising inner and outer laminations of different grades (strength classes) and species (or species combinations), (CEN BS EN1194, 1999).

In this work three different densities (GL20h, GL24h and GL32h) for wood are indicated and shown in figure 4 . The emissivity of the wood material was considered equal to 0.8 .

\subsection{Gypsum Thermal Properties}

Using the literature, it is possible to find the gypsum thermal properties (Piloto, Khetata, \& Gavillán, 2018), (Frangi, Schleifer, Fontana \& Hugi, 2010). In this work two different types of gypsum material were used from the references, (Rahmanian \& Wang, 2009), (Frangi, Schleifer, Fontana \& Hugi, 2010).

Figures 6, 7 and 8 present the specific heat, thermal conductivity and density of each gypsum type, respectively.

The thermal conductivity of gypsum is relatively complex due to the effect of moisture and radiation in the pores. The specific heat taking into account the different chemical reactions during heating presents two peaks, (Frangi, Schleifer, Fontana \& Hugi, 2010). The first peak represents the two endothermic reactions of the gypsum dehydration and the second peak represents the calcium magnesium carbonate decomposition, (Frangi, Schleifer, Fontana \& Hugi, 2010). 
The density is affected by the mass loss, that remains almost unchanged up to $100^{\circ} \mathrm{C}$ and between $100-160^{\circ} \mathrm{C}$ decreases $15-17 \%$ as moisture is driven off, and then remains fairly constant. The emissivity of this material was considered equal to 0.8 .

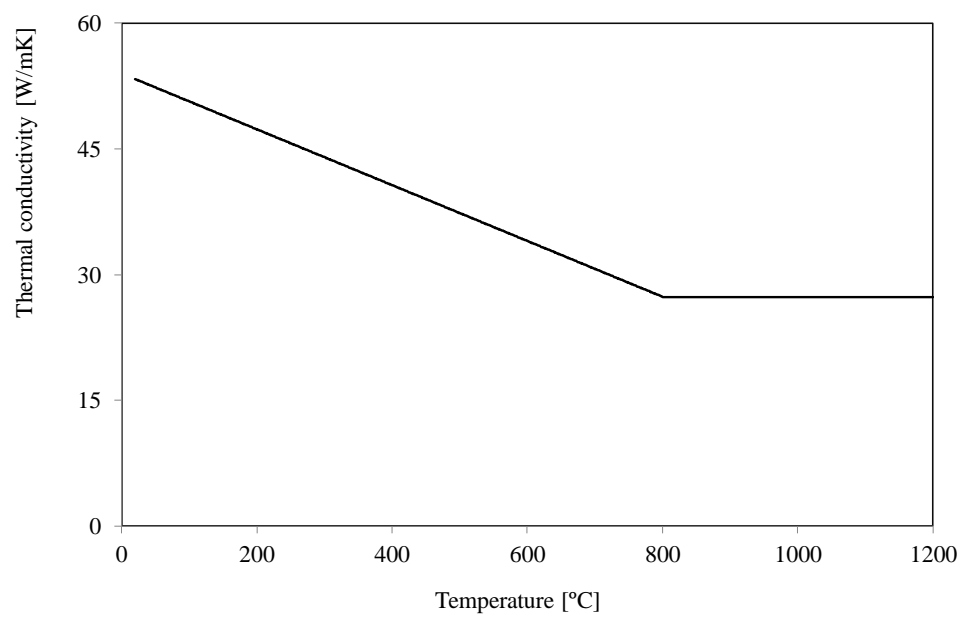

Figure 1: Thermal Conductivity of Steel

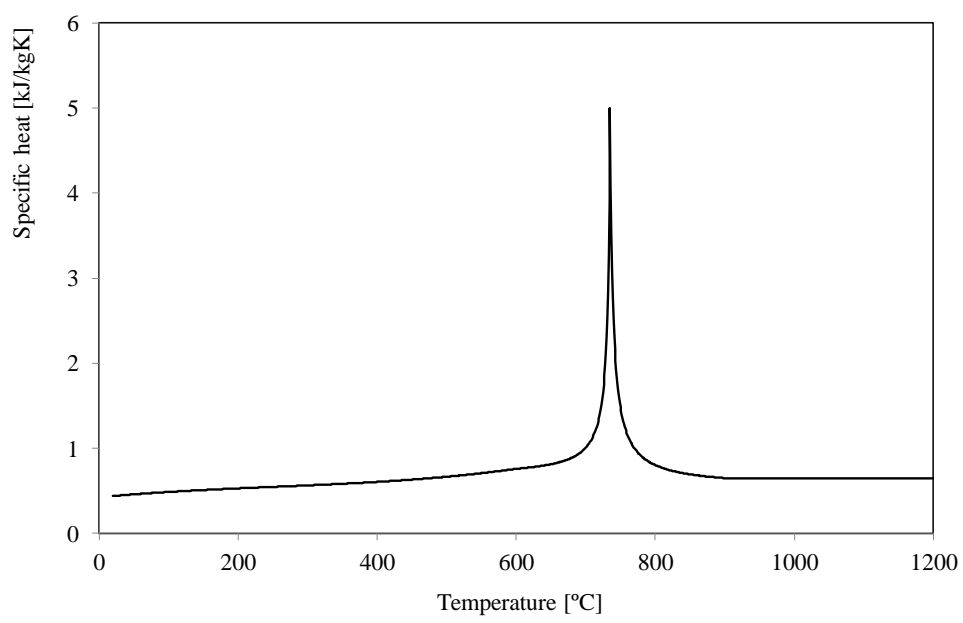

Figure 2: Specific Heat of Steel 


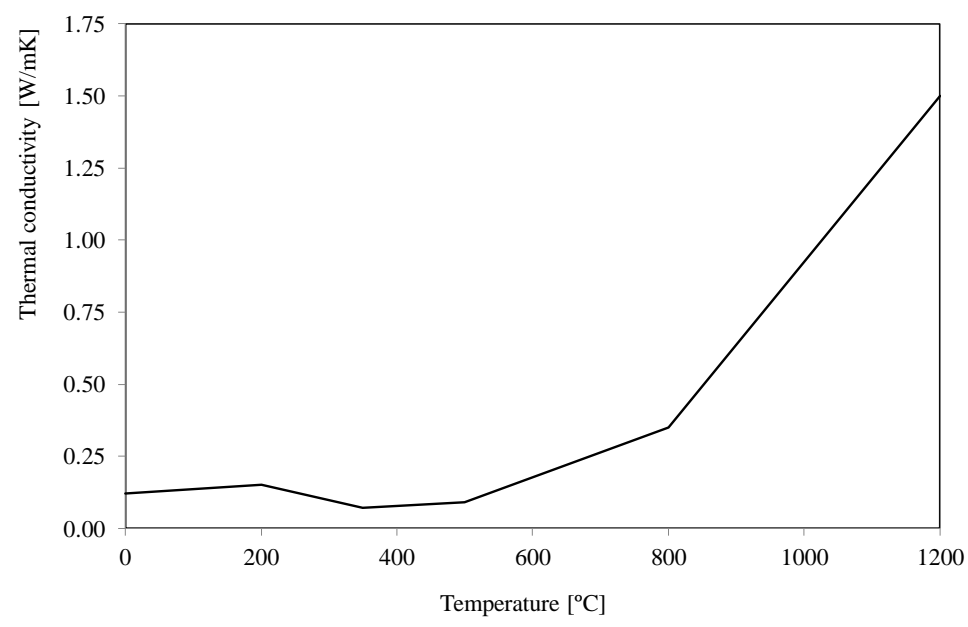

Figure 3: Thermal Conductivity of Wood

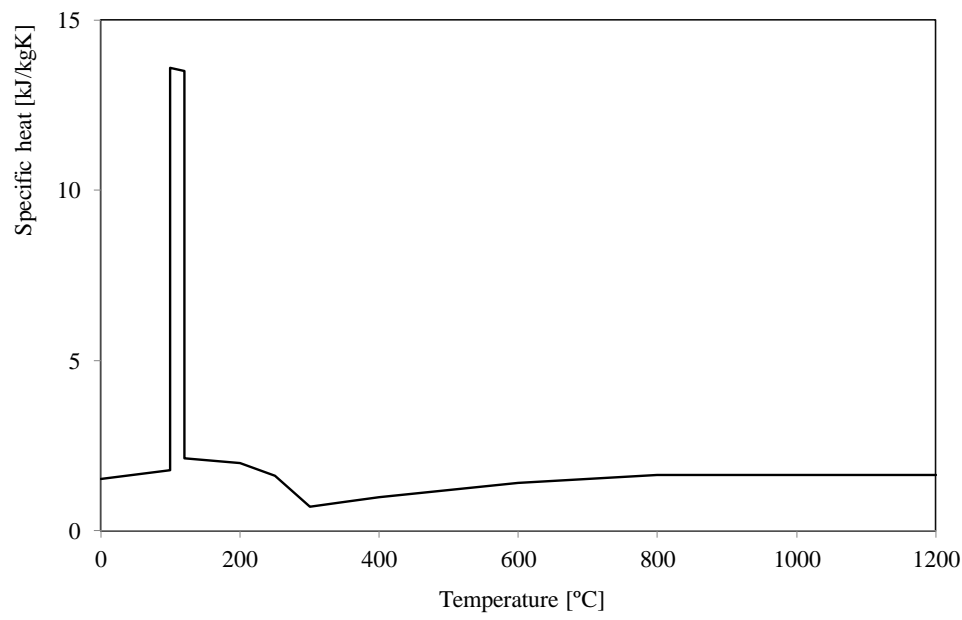

Figure 4: Specific Heat of Wood

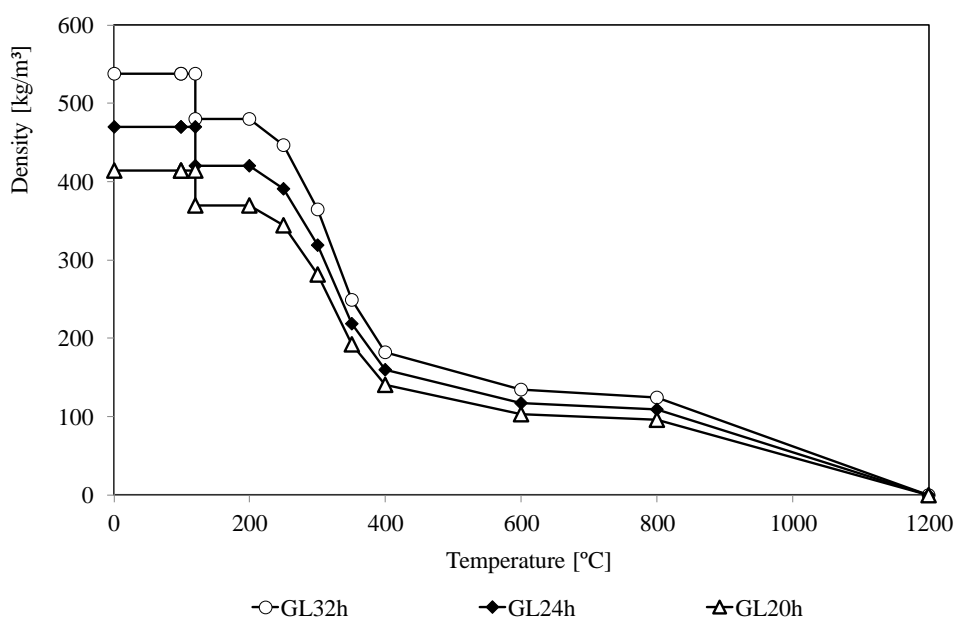

Figure 5: Density of Wood (GL2Oh, GL24h and GL32h) 


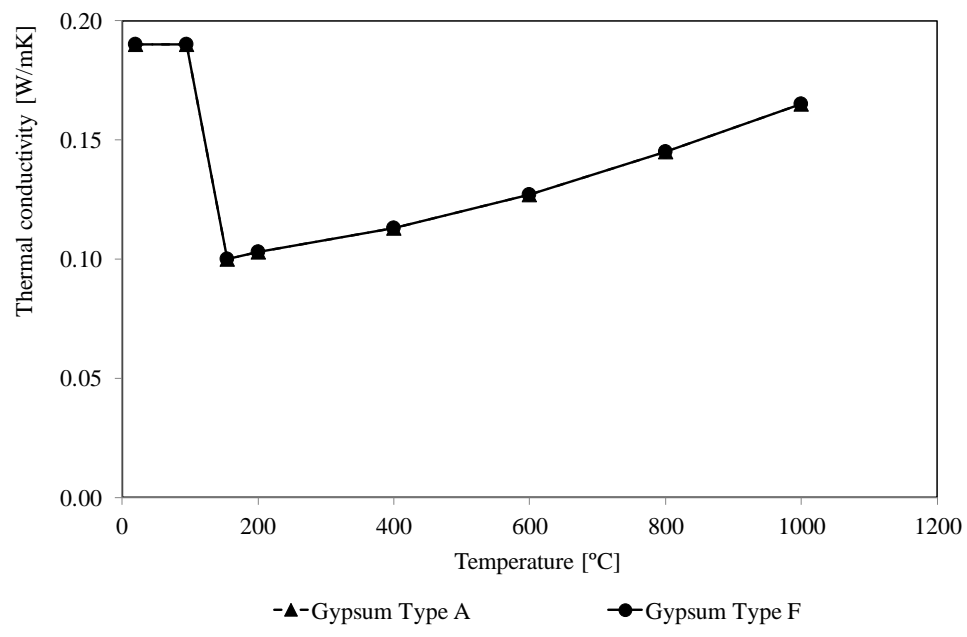

Figure 6: Thermal Conductivity of Gypsum

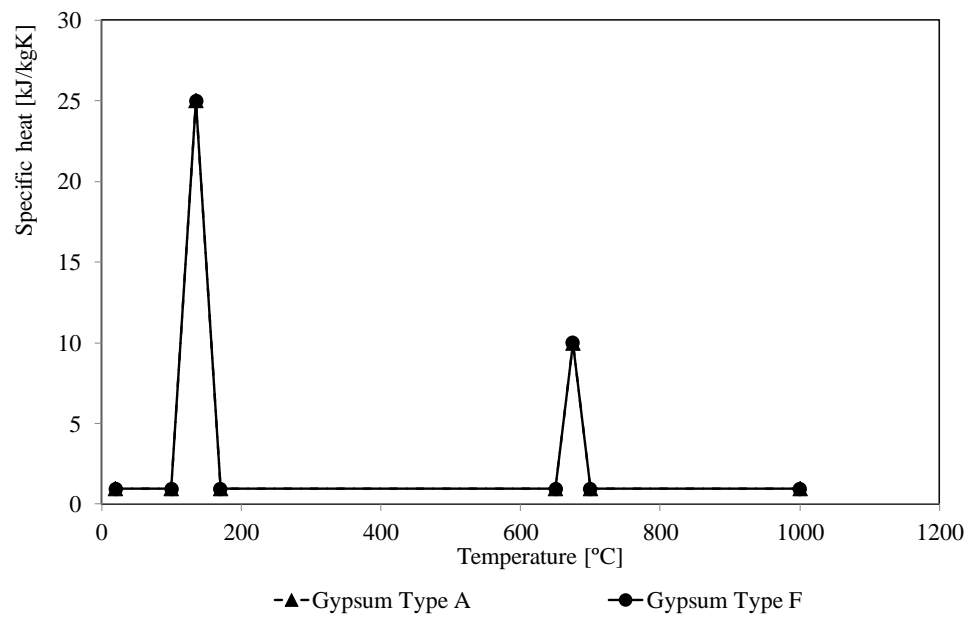

Figure 7: Specific Heat of Gypsum

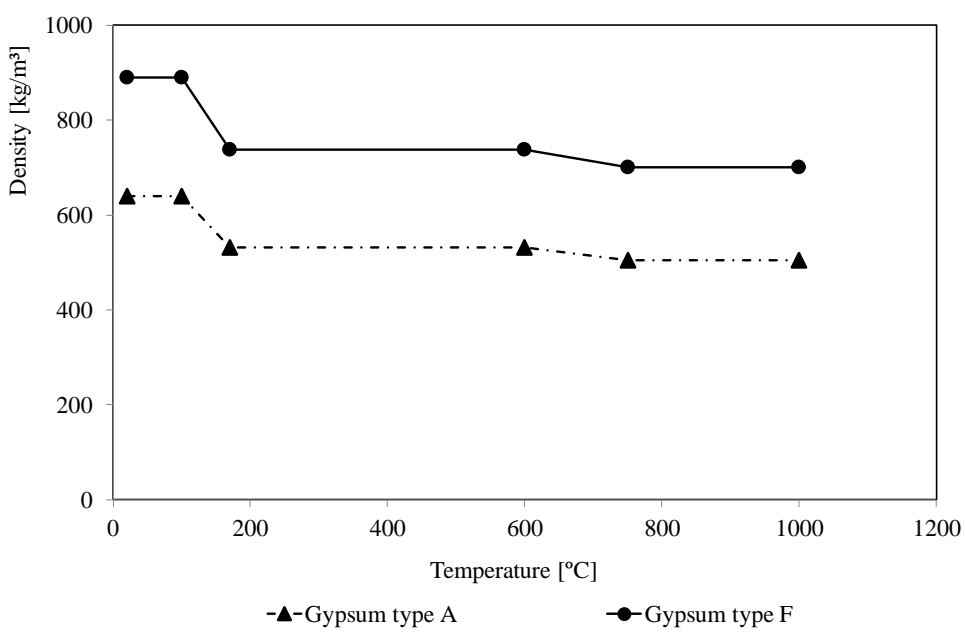

Figure 8: Density of Gypsum 


\section{Thermal and Transient Numerical Model}

To simulate the fire resistance of the wood connection, a numerical thermal and transient model based on the finite element method was used, using the previously designed connections at room temperature. The finite element method is a powerful method which is widely used to solve different problems in engineering. The modelling process of the model consist in dividing by finite elements and interconnected at common nodes with a specific number of degrees of freedom. Due to the geometry symmetry, the numerical calculation was performed in two dimensional crosssections, representing a section in wood or in wood-steel material for unprotected and protected connections, figures 9 and 10.

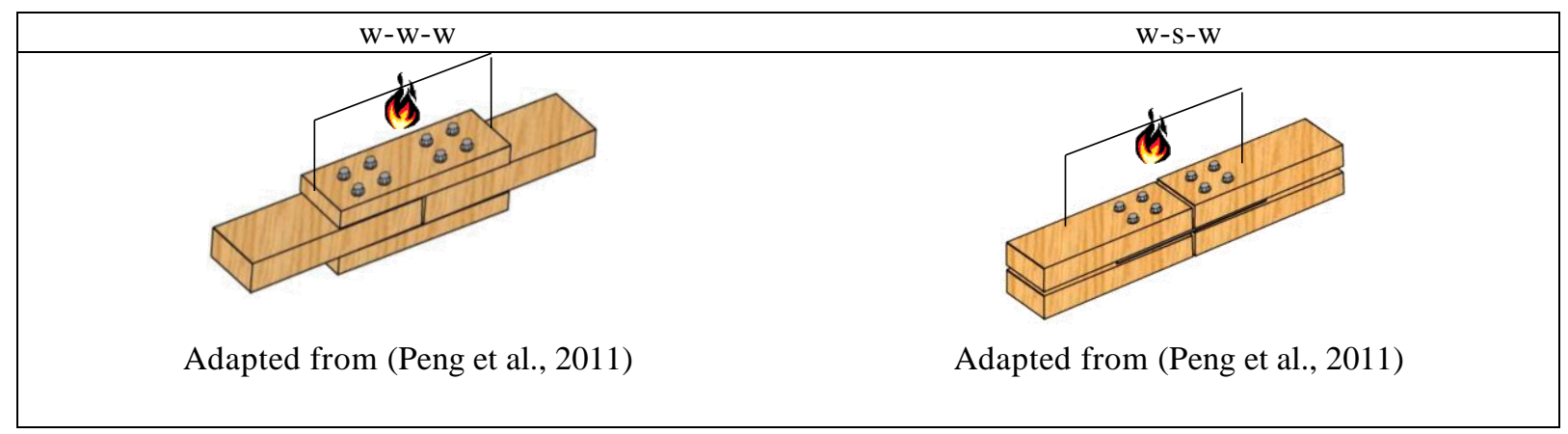

Figure 9: $W-W-W$ and $W-S-W$ Connections

The finite element chosen has eight nodes and one degree of freedom per node, correspondent to the temperature. The size of the finite element is equal to $2 \mathrm{~mm}$ of length, (Fonseca, Silva \& Leite, 2019). In all models a perfect thermal contact between all materials were considered and the relationship between the temperature and the thermal properties are adopted. For this reason, the non-linearity due to the thermal materials properties dependence will be taken into account. The material properties for wood and steel are represented in two different colours, blue and violet respectively, and the insulation material is represented in red colour, figure 10 .

The boundary conditions used are related to the convection and radiation due to the exposed fire in front of the external surface of the protected or unprotected connection. The initial temperature in the model was considered equal to $20^{\circ} \mathrm{C}$. The environment surface emissivity in the connection is 1.0, Eurocode 1 part 1-2 (CEN EN1991-1-2, 2002). The external surface of the connection is exposed to the standard fire curve ISO834 during 3600 seconds and the convection coefficient is $25 \mathrm{~W} / \mathrm{m}^{2} \mathrm{~K}$, Eurocode 1 part 1-2 (CEN EN1991-1-2, 2002). 
$\mathrm{W}-\mathrm{W}-\mathrm{W}$

W-S-W

\begin{tabular}{|c|c|}
\hline $\begin{array}{l}\text { Unprotected connection } \\
\text { (dowel diameter=8mm) }\end{array}$ \\
Protected connection \\
Gypsum Type A, \\
hp=23mm
\end{tabular}

Figure 10: Meshes of Unprotected and Protected Connections

\section{Results and Discussion}

Figure 11 presents the numerical results of the wood char layer and the temperature inside the connection at two different time instants.

It is possible to notice that the steel remains at a lower temperature if the exposure time is small, due to the insulation by the wood elements, and the core wood remains at room temperature. Nevertheless, in the vicinity of the dowels elements the wood material receives the heat effect by the steel conduction. When the fire exposure increases the steel material provides higher heat flux inside the connection. For this situation, both materials participate in the char layer development of the connection. For thirty minutes of fire exposure, the wood material presents mass loses and both unprotected connections have no fire resistance. Nevertheless, the W-S-W connection presents the worst effect due to the steel plate as a central member inducing higher heat inside.

The charring rate was numerically calculated according to three different positions for the fire exposure time instant at 15min: $\mathrm{k} 1$ faraway of the steel dowels, $\mathrm{k} 2$ in the vicinity of the dowel and $\mathrm{k} 3$ between two dowels. 
W-S-W

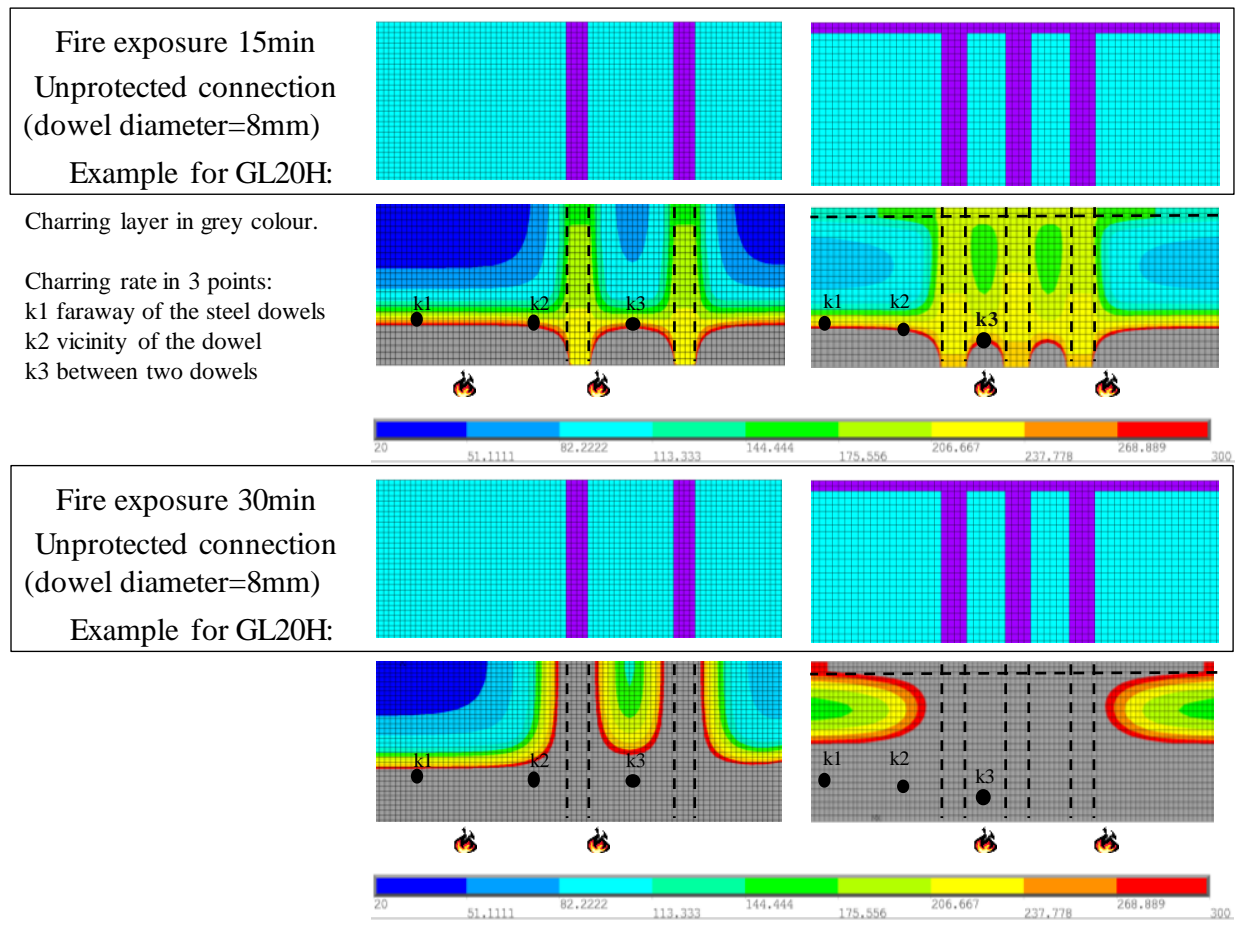

Figure 11: Char Layer of Unprotected Connections

Table 1 presents the values of the charring rate dependent on each wood density. K1 gives values of charring rate close to the proposed values in Eurocode 5, part 1-2 (CEN EN1995-1-2, 2004). In $\mathrm{W}-\mathrm{W}-\mathrm{W}$ connection, $\mathrm{k} 2$ and $\mathrm{k} 3$ present higher charring rate, due to the vicinity to the steel dowel. In $\mathrm{W}-\mathrm{S}-\mathrm{W}$ connection $\mathrm{k} 2$ and $\mathrm{k} 3$ present a decreased charring rate at $15 \mathrm{~min}$ of fire exposure due to the effect of the vicinity steel members, the internal steel plate at lower temperature and the smaller controlled wood area. When fire increases higher charring rate is produced and the heat conduction by the steel affects all components, more pronounced in $\mathrm{W}-\mathrm{S}$ $\mathrm{W}$ connection. In general, the charring rate decreases with the wood density and in connections with a central steel plate W-S-W.

Table 1: Charring Rate of the $W-W-W$ and $W-S-W$ Connections at 15 min of Fire Exposure

\begin{tabular}{|lcccccc|}
\hline \multirow{2}{*}{ Points } & \multicolumn{2}{c}{ 1-wood-wood-wood connection } & \multicolumn{3}{c|}{ 2-wood-steel-wood connection } \\
& GL20H & GL24H & GL32H & GL20H & GL24H & GL32H \\
k1 & 0.77 & 0.72 & 0.67 & 0.80 & 0.77 & 0.70 \\
k2 & 1.00 & 0.93 & 0.80 & 0.65 & 0.63 & 0.60 \\
k3 & 1.13 & 1.00 & 0.87 & 0.51 & 0.47 & 0.43 \\
\hline
\end{tabular}




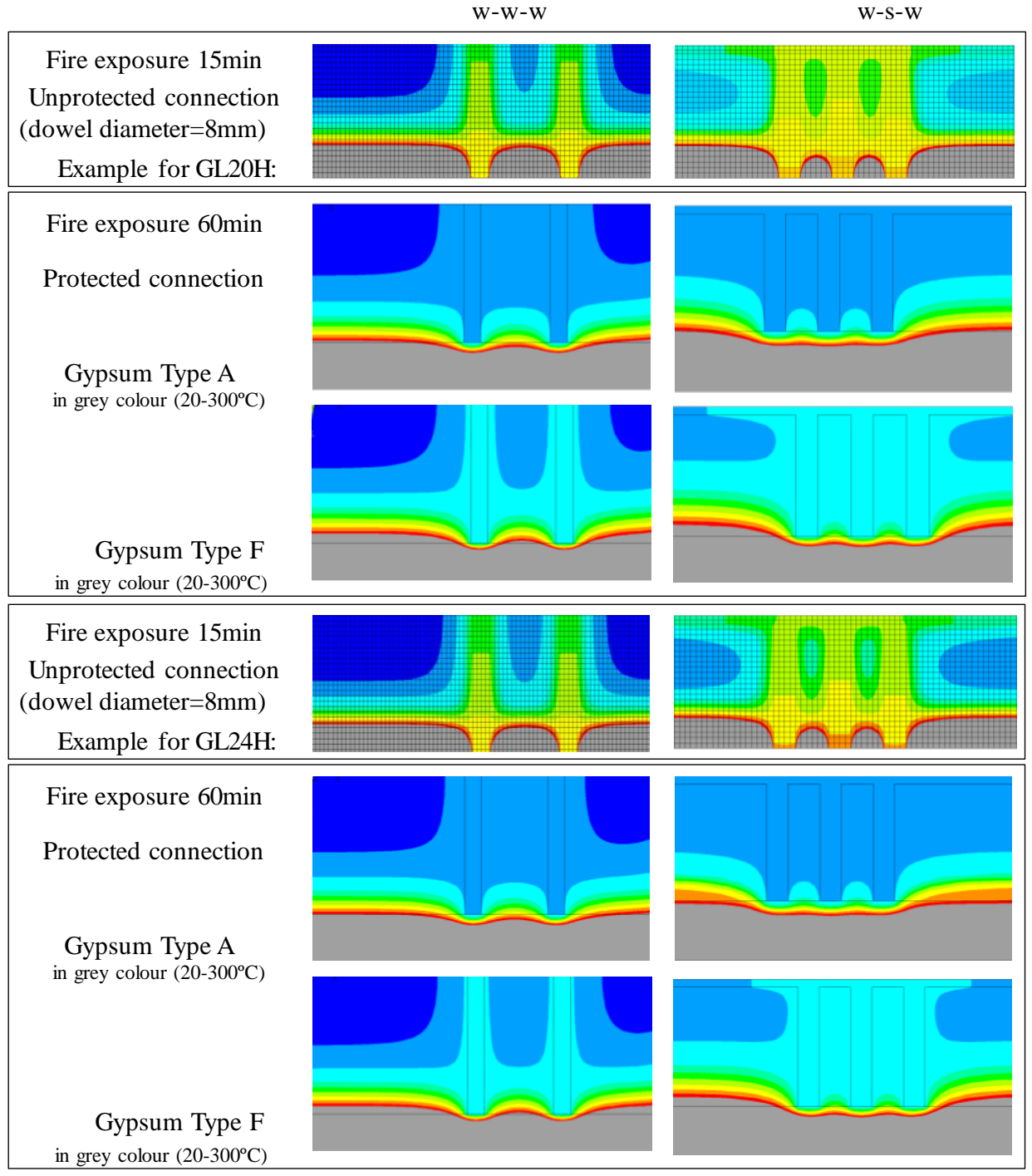

\begin{tabular}{|c|}
\hline $\begin{array}{c}\text { Fire exposure } 15 \mathrm{~min} \\
\text { Unprotected connection } \\
\text { (dowel diameter=8mm) } \\
\text { Example for GL32H: }\end{array}$ \\
Fire exposure 60min \\
Protected connection \\
Gypsum Type A \\
in grey colour $\left(20-300^{\circ} \mathrm{C}\right)$
\end{tabular}

Figure 12: $W-W-W$ and $W-S-W$ Connections 
Figure 12 shows the temperature field in the connections with dowels diameter $8 \mathrm{~mm}$, without and with insulation material (gypsum type A and F), considering the effect of the wood material density. The main objective is verifying the effect of wood density in the char layer evolution for unprotect connections, and test the ability of the protected connections at 60min of fire exposure.

The effect of increased wood density is obvious on unprotected connections where the temperature field is higher for the lowest wood density and with the major number of steel elements. In general, for protected connections the calculated thickness for the plasterboard gypsum material (A or F) protected the connection during one hour of fire exposure. It is also noticed that, at that time, the W-S-W connections have higher internal heating, and it is verified that the gypsum type F allows more heat internally to the wood. Also in these connections, despite a smaller effect, the lower wood density induces greater heat passage.

\section{Conclusions}

In this work, different methodologies applied to the wood connections design were presented: analytical equations to assess a safe cross-section due to an applied tensile load and two dimensional numerical simulations focused on thermal and transient analysis to obtain the wood char layer.

As general conclusions, the number of fasteners increases with the applied load according to standards at room temperature, lower dowels diameters have higher effect in the number of fasteners, at fire exposure the steel fasteners bring the heat to inside the connections, and the different wood densities affect the thermal behaviour and the charring rate evolution.

The numerical method, for protected and unprotected connections, shows to be a good process to understand the behaviour of the connections under fire, in addition to the simplified equations. Using only the Eurocode 5 part 1-2 (CEN EN1995-1-2, 2004), it is impossible to understand the fire evolution through and inside the connection.

The charring rate is considered as a constant value in all the connection, however in the numerical results is verified that the charring rate varies due to steel heat conduction and the material density effect. The numerical simulations were very relevant and to facilitate to understand the fire behaviour of the connections. 


\section{References}

Andrea Frangi, Vanessa Schleifer, Mario Fontana, \& Erich Hugi. (2010). Experimental and Numerical Analysis of Gypsum Plasterboards in Fire. Fire Technology, 46, 149-167. https://doi.org/10.1007/s10694-009-0097-5

Aissa, A., Fonseca, E.M.M., \& Lamri, B. (2017). Protected and Unprotected W-W-W Connection at Elevated Temperatures. Daniel Alvear (Ed.), Research and Advanced Technology in Fire Safety, Universidad Cantabria, D.L. SA 739-2017, ISBN: 978-84-8102-832-4, 407.

CEN, EN1991-1-2 - Eurocode 1: Actions on Structures, Part 1-2: General actions - Actions on Structures Exposed to Fire, Brussels, 2002.

CEN, EN1995-1-1: Eurocode 5: Design of timber structures. Part 1-1: General Common rules and rules for buildings, Brussels, 2004.

CEN, EN1995-1-2: Eurocode 5: Design of timber structures. Part 1-2: General Structural fire design, Brussels, 2004.

CEN, EN1993-1-2: Eurocode 3: Design of steel structures. Part 1-2: General rules - Structural Fire Design, Brussels, 2005.

CEN, BS EN1194: Timber Structures - Glued laminated timber - Strength classes and determination of characteristic values, British Standard, 1999.

Eckart Resch, \& Michael Kaliske. (2012). Numerical analysis and design of double-shear doweltype connections of wood. Engineering Structures, 41, 234-241. https://doi.org/10.1016/j.engstruct.2012.03.047

Fonseca, E. M. M., Silva, L., \& Leite, A. S. P. (2019). Fire safety of wood-steel connections, Edited by APMTAC, Maria Amélia, Joaquim Barbosa et al. (Eds.), 4th International Conference on Numerical and Symbolic Computation Developments and Applications Developments and Applications, Porto, ISBN 978-989-99410-5-2, 109-118.

Fonseca, E. M. M., \& Gouveia, P. J. V. (2018). Analysis of simply supported wood beams at ambient and high temperatures. International Journal of Engineering \& Technology, 7(2.23), 180-183. https://doi.org/10.14419/ijet.v7i2.23.11911

Fonseca, E. M. M., Coelho, D. C. S. \& Barreira, L. M. S. (2012). Structural Safety in Wooden Beams under Thermal and Mechanical Loading Conditions. International Journal of Safety and Security Engineering, 2(3), 242-255. https://doi.org/10.2495/SAFE-V2-N3-242-255 
Hadjisophocleus, G., Mohammad, M., Peng, L., \& Mehaffey, J. (2011). On the Fire Performance of Double-shear Timber Connections. Fire Safety Science, 10(3), 1207-1218. https://doi.org/10.3801/IAFSS.FSS.10-1207

Rahmanian, I., \& Wang, Y. (2009). Thermal Conductivity of Gypsum at High Temperatures a Combined Experimental and Numerical Approach. Acta Polytechnica, 49(1), 16-20.

Peng, L., Hadjisophocleous, G., Mehaffey, J., \& Mohammad, M. (2011). On the Fire Performance of Double-shear Timber Connections. Fire Safety Science, 42, 1207-1218. https://doi.org/10.3801/IAFFS.FSS.10-1207

Martins, D. A. R, \& Fonseca, E. M. M. (2018). Fire Behaviour of Protected W-S-W Connections with a Steel Plate as the Central Member and Different Dowels Diameter. MATTER: International Journal of Science and Technology, 4(3), 60-78. https://doi.org/10.20319/mijst.2018.43.6078

Piloto, A. G. P., Khetata, M. S., \& Gavillán, A. B. R. (2018). Loadbearing capacity of LSF walls under fire exposure. MATTER: International Journal of Science and Technology, 4(3), 104-124. https://doi.org/10.20319/mijst.2018.43.104124 